\title{
Protective effect of 3,5-dicaffeoyl-epi-quinic acid against UVB-induced photoaging in human HaCaT keratinocytes
}

\author{
JUNG HWAN OH ${ }^{1}$, FATIH KARADENIZ ${ }^{1,2}$, JUNG IM LEE ${ }^{2}$, YOUNGWAN SEO ${ }^{3,4}$ and CHANG-SUK KONG ${ }^{1,2}$ \\ ${ }^{1}$ Department of Food and Nutrition; ${ }^{2}$ Marine Biotechnology Center for Pharmaceuticals and Foods, College of Medical \\ and Life Sciences, Silla University, Busan 46958; ${ }^{3}$ Division of Marine Bioscience, College of Ocean Science and Technology, \\ Korea Maritime and Ocean University, Busan 49112; ${ }^{4}$ Department of Convergence Study on Ocean Science and Technology, \\ Ocean Science and Technology School, Korea Maritime and Ocean University, Busan 49112, Republic of Korea
}

Received August 17, 2018; Accepted March 28, 2019

DOI: $10.3892 / \mathrm{mmr} .2019 .10258$

\begin{abstract}
Derivatives of caffeoylquinic acid (CQA) have been studied and reported as potent bioactive molecules possessing various health benefits including antioxidant and anti-inflammatory activities. In the present study, the protective effect of 3,5-dicaffeoyl-epi-quinic acid (DCEQA) isolated from Atriplex gmelinii on UVB-induced damages was investigated in human HaCaT keratinocytes. The effect of DCEQA against UVB-induced oxidative stress-mediated damages was determined measuring its ability to alleviate UVB-induced elevation of oxidative stress, proinflammatory response and antioxidant enzyme suppression through nuclear factor-like 2 (Nrf2). Treatment with DCEQA hindered the generation of intracellular reactive oxygen species. Increased levels of proinflammatory cytokines TNF- $\alpha$, COX-2, IL-6 and IL-1 $\beta$ following UVB exposure were suppressed by the introduction of DCEQA. Additionally, DCEQA upregulated the mRNA and protein expression of antioxidant enzymes superoxide dismutase-1 and heme oxygenase- 1 which were inhibited under UVB irradiation. Antioxidant enzyme regulation transcription factor Nrf2 was also upregulated in the presence of DCEQA. These results suggest that DCEQA prevents photoaging via protection of keratinocytes from UVB irradiation by ameliorating the oxidative stress and pro-inflammatory response.
\end{abstract}

\section{Introduction}

The aging of skin progresses by two contributing causes: time and photodamage. Chronological skin aging progresses by time and is observed as damage-prone skin with a dry and thin

Correspondence to: Professor Chang-Suk Kong, Department of Food and Nutrition, College of Medical and Life Sciences, Silla University, 140 Baekyang-daero Blvd, 700 Beon-gil Road, Busan 46958, Republic of Korea

E-mail: cskong@silla.ac.kr

Key words: 3,5-dicaffeoyl-epi-quinic acid, Atriplex gmelinii, nuclear factor-like 2, oxidative stress, UVB epidermis (1). Photoaging, which is stimulated by ultraviolet (UV) irradiation, is characterized by damage to skin DNA, degraded collagen build-up and excessive oxidative stress $(2,3)$. The advancement of aging due to UV irradiation occurs in specific skin cells called keratinocytes, fibroblasts and neutrophils. Among the different types of UV rays that can reach the skin surface, UVB exposure is considered to be the most harmful type of UV irradiation that acts predominantly on the epidermis layer and keratinocytes $(4,5)$. UVB irradiation activates the nuclear factor $-\kappa \mathrm{B}(\mathrm{NF}-\kappa \mathrm{B})$ pathway resulting in the elevated activity and expression of matrix metalloproteinases and cytokines (6). Activated cytokines induce the degradation of the extracellular matrix. Continued UVB exposure causes accumulation of the degraded extracellular matrix and manifests itself as wrinkles and brittle skin (7).

UVB irradiation is also known to generate reactive oxygen species (ROS) and is linked to inflammatory responses in skin such as sunburn, erythema and edema $(8,9)$. The main share of skin damage that occurs by prolonged UVB irradiation is associated with ROS and ROS-linked inflammation. The harmful effects of ROS in skin are generally negated by antioxidant defense mechanism of the body consisting of antioxidant enzymes and free radical scavenging molecules. However, excessive ROS as a result of continuous UVB exposure lead to reaction with fatty acids and initiation of lipid peroxidation, which at the end causes cellular damage $(10,11)$. On the other hand, UVB-stimulated overexpression of COX-2 and activation of $N F-\kappa B$ play a crucial role in the progression of the inflammatory response in the skin together with the activation of several cytokines including tumor necrosis factor (TNF)- $\alpha$, interleukin-6 (IL-6) and IL-1 $\beta$ (12-14). UVB-induced overexpression of inflammatory cytokines and their roles in the deteriorating effects on the skin has been reported in detail (15).

Natural antioxidants, mainly bioactive substances from plants are important compounds against the photoaging effect of solar irradiation (16). These bioactive agents from natural sources are potent antioxidants, which also can alleviate inflammatory responses (17), help skin to recover from photodamage $(18,19)$ and also prevent further solar radiation damages (20). Reports indicate promising health beneficial effects of dietary phytochemicals in protecting skin 
damage and nourishing the skin following photodamage (21). Caffeoylquinic acid (CQA) is one of the naturally occurring abundant phytochemicals found in a variety of sources including but not limited to coffee beans, sweet potato, propolis and other plants. In the literature, CQA derivatives have been reported as bioactive agents that may be regarded as promising antioxidants (22), antibacterial (23) and antitumor (24) agents. Recently, various CQA-related derivatives have been credited as inhibitors of UV-linked oxidative stress and skin damage (25-27). In addition, studies have shown that they alleviate skin disorders secondary to their free radical scavenging effect (25). In this context, the present study aimed to analyze the potential of 3,5-dicaffeoyl-epi-quinic acid (DCEQA) against UVB-induced oxidative stress and inflammatory response in the $\mathrm{HaCaT}$ immortal keratinocyte cell line.

\section{Materials and methods}

Plant materials and isolation. The sample $(3 \mathrm{~kg})$ of $A$. gmelinii was air dried and cut into small pieces prior to maceration. Ground samples were extracted twice with methylene chloride $\left(\mathrm{CH}_{2} \mathrm{Cl}_{2}\right)$ for $24 \mathrm{~h}$ at room temperature. The extract was concentrated and dried by evaporation in vacuo, using a vacuum rotary evaporator (RV 10 Series, IKA, Staufen, Germany), yielding a sticky crude extract. Remaining ground samples were then subjected to extraction again, twice with methanol $(\mathrm{MeOH})$, using the same procedure as above. The combined crude extracts from the $\mathrm{CH}_{2} \mathrm{Cl}_{2}$ and $\mathrm{MeOH}$ extraction were partitioned between $\mathrm{CH}_{2} \mathrm{Cl}_{2}$ and water $\left(\mathrm{H}_{2} \mathrm{O}\right)$. The dichloromethane layer was evaporated under reduced pressure and the residue was repartitioned between $n$-hexane and $85 \%$ aqueous $\mathrm{MeOH}$. The $\mathrm{H}_{2} \mathrm{O}$ layer was also further partitioned between $n$ - $\mathrm{BuOH}$ and $\mathrm{H}_{2} \mathrm{O}$. A portion of the $n-\mathrm{BuOH}$ fraction $(10.74 \mathrm{~g})$ was further subjected to separation by fractionation between EtOAc and $\mathrm{H}_{2} \mathrm{O}$. The EtOAc layer was concentrated using a rotary evaporator to obtain an extract of $3.10 \mathrm{~g}$, a portion $(74.4 \mathrm{mg})$ of which was subjected to isolation via preparative thin layer chromatography on silica gel using EtOAc/ $\mathrm{MeOH} / \mathrm{H}_{2} \mathrm{O}$ (30:5:4) as a solvent and yielded the compound $(18 \mathrm{mg})$ as a white powder. The molecular formula of the compound was defined as $\mathrm{C}_{25} \mathrm{H}_{24} \mathrm{O}_{12}$ and its purity and structure were confirmed with HPLC and ${ }^{1} \mathrm{H}$ - and ${ }^{13} \mathrm{C}$-NMR spectra results (Table I), which were compared with previous reports of similar compounds (28) for further identification of the compound. The compound was identified as 3,5-dicaffeoyl-epi-quinic acid (DCEQA) and was dissolved in methanol and diluted with Dulbecco's modified Eagle's Medium (DMEM) for further experiments.

Cell culture and UVB irradiation. Human HaCaT immortal keratinocyte cell line was purchased from Cell Line Service (Eppelheim, Germany). Cells were cultured in DMEM (Gibco; Thermo Fisher Scientific, Inc., Waltham, MA, USA) supplemented with $10 \%$ fetal bovine serum (FBS), $100 \mu \mathrm{g} / \mathrm{ml}$ penicillin-streptomycin antibiotics and $2 \mathrm{mM}$ glutamine (Gibco-BRL; Thermo Fisher Scientific, Inc.) and incubated in a humidified atmosphere of $5 \% \mathrm{CO}_{2}$ at $37^{\circ} \mathrm{C}$. Cells were trypsinized and subcultured after reaching $\sim 90 \%$ confluency for further experiments.

Cells were irradiated by UVB using a Bio-Sun UV Irradiation System (Vilber Lourmat, Marine, France) fitted with a 312-nm UVB source designed for microplates. HaCaT cells grown in microplates were irradiated at $15 \mathrm{~mJ} / \mathrm{cm}^{2}$ UVB dose, which is the approximate dose of UVB irradiation $(24 \mathrm{~h})$ thought to induce oxidative stress-mediated photoaging in HaCaT Cells without significant mortality or malformation $(29,30)$. The dose was validated in preliminary experiments on $\mathrm{HaCaT}$ cells following $24 \mathrm{~h}$ exposure (data not shown). Cells were irradiated in phosphate-buffered saline (PBS) without the plastic lid. When the irradiation received matched the desired programmed energy, the UVB irradiation stopped automatically, and subsequently the cells were incubated with DMEM without FBS until analysis.

Cell viability assay. The viability of $\mathrm{HaCaT}$ cells was analyzed by using ability of viable cells to convert MTT to an insoluble formazan product that can be quantified with a colorimetric method. Cells were cultured in 96-well plates and incubated for $24 \mathrm{~h}$ prior to washing with PBS and treatment with different concentrations $(1,5$ and $10 \mu \mathrm{M})$ of DCEQA introduced with a serum-free fresh medium. After incubation for $24 \mathrm{~h}$, the supernatant was removed and $100 \mu \mathrm{l}$ of $1 \mathrm{mg} / \mathrm{ml}$ MTT in PBS was added to the culture wells. The MTT solution was then removed after $4 \mathrm{~h}$ of incubation and $50 \mu \mathrm{l}$ DMSO was introduced to each well to stop the reaction and quantify the converted MTT. Optical density of the wells was measured at a wavelength of $540 \mathrm{~nm}$ using a GENios ${ }^{\circledR}$ microplate reader (Tecan Group, Ltd., Mannedorf, Switzerland). MTT test was conducted in triplicate wells for each condition and repeated at least thrice. Viability of the cells was plotted as a relative percentage against the untreated control cell group.

Determination of intracellular ROS generation. Intracellular generation of ROS was determined using an oxidizing radical species-sensitive dye 2',7'-dichlorofluorescin diacetate (DCFH-DA). HaCaT cells that were grown in fluorescence microtiter 96-well plates and incubated for $24 \mathrm{~h}$ were loaded with $20 \mu \mathrm{M}$ DCFH-DA in PBS and incubated for $20 \mathrm{~min}$ in the dark at room temperature. Cells were then treated with different concentrations of DCEQA and incubated for $1 \mathrm{~h}$. After washing the cells with PBS three times, $500 \mu \mathrm{M} \mathrm{H}_{2} \mathrm{O}_{2}$ dissolved in PBS was added to the cells. Using a GENios ${ }^{\circledR}$ microplate reader (Tecan Group, Ltd.) the plate fluorescence intensity was read every $30 \mathrm{~min}$ for $3 \mathrm{~h}$ at an excitation wavelength of $485 \mathrm{~nm}$ and emission wavelength of $528 \mathrm{~nm}$ to detect the 2',7'-dichlorofluorescein (DCF) which was formed via oxidation of DCFH in the cells by ROS. Dose-dependent and time-dependent changes in DCF fluorescence intensity were plotted and compared with untreated control and not irradiated blank cells.

Reverse transcription-semi quantitative polymerase chain reaction ( $R T$-sqPCR) analysis. Total RNA was isolated from UVB-irradiated and unexposed HaCaT keratinocytes treated with/without DCEQA using TRIzol ${ }^{\circledR}$ reagent (Invitrogen; Thermo Fisher Scientific, Inc.). For synthesis of cDNA, RNA (2 $\mu \mathrm{g})$ and oligo(dT) were mixed in RNase-free water. This mixture was denatured at $70^{\circ} \mathrm{C}$ for $5 \mathrm{~min}$ and cooled immediately. RNA reverse transcription was carried out in a master mix containing $1 \mathrm{X}$ RT buffer, $1 \mathrm{mM}$ dNTPs, $500 \mathrm{ng}$ oligo(dT), 140 units M-MLV reserve transcriptase 
Table I. 1H and 13C NMR spectral data for DCEQA.

\begin{tabular}{|c|c|c|}
\hline Position & $\delta_{\mathrm{H}}$ & $\delta_{\mathrm{C}}$ \\
\hline 1 & & $76.3 \mathrm{~s}$ \\
\hline 2 & $2.11(2 \mathrm{H}, \mathrm{m})$ & $40.6 \mathrm{t}$ \\
\hline 3 & $5.55(1 \mathrm{H}, \mathrm{dt}, \mathrm{J}=10.0,5.8 \mathrm{~Hz})$ & $72.4 \mathrm{~d}$ \\
\hline 4 & $3.91(1 \mathrm{H}, \mathrm{dd}, \mathrm{J}=9.9,3.4 \mathrm{~Hz})$ & $73.0 \mathrm{~d}$ \\
\hline 5 & $5.39(1 \mathrm{H}, \mathrm{m})$ & $74.4 \mathrm{~d}$ \\
\hline 6 & $\begin{array}{l}2.04(1 \mathrm{H}, \mathrm{m}), 2.28(1 \mathrm{H}, \mathrm{dd} \\
\mathrm{J}=15.2,3.4 \mathrm{~Hz})\end{array}$ & $37.5 \mathrm{t}$ \\
\hline $1^{\prime}$ & & $127.8 \mathrm{~s}, 128.0 \mathrm{~s}$ \\
\hline $2^{\prime}$ & $\begin{array}{l}\text { 7.06, } 7.08(\text { each } 1 \mathrm{H}, \\
\mathrm{d}, \mathrm{J}=2.0 \mathrm{~Hz})\end{array}$ & $115.2 d$ \\
\hline $3^{\prime}$ & & $146.8 \mathrm{~s}, 146.9 \mathrm{~s}$ \\
\hline $4^{\prime}$ & & $149.2 \mathrm{~s}, 149.4 \mathrm{~s}$ \\
\hline $5^{\prime}$ & $6.78(2 \mathrm{H}, \mathrm{d}, \mathrm{J}=8.2 \mathrm{~Hz})$ & $116.4 d$ \\
\hline $6^{\prime}$ & $\begin{array}{l}6.96,6.97(\text { each } 1 \mathrm{H}, \mathrm{dd}, \\
\mathrm{J}=8.2,2.0 \mathrm{~Hz})\end{array}$ & $122.9 \mathrm{~d}$ \\
\hline $7^{\prime}$ & $\begin{array}{l}7.59,7.62(\text { each } 1 \mathrm{H}, \mathrm{d}, \\
\mathrm{J}=15.8 \mathrm{~Hz})\end{array}$ & $146.6 \mathrm{~d}, 146.6 \mathrm{~d}$ \\
\hline $8^{\prime}$ & $\begin{array}{l}6.31,6.43(\text { each } 1 \mathrm{H}, \mathrm{d}, \\
\mathrm{J}=15.8 \mathrm{~Hz})\end{array}$ & $115.4 \mathrm{~d}, 115.9 \mathrm{~d}$ \\
\hline $9^{\prime}$ & & $169.0 \mathrm{~s}, 169.4 \mathrm{~s}$ \\
\hline $\mathrm{COOH}$ & & $181.3 \mathrm{~s}$ \\
\hline
\end{tabular}

Measured in $\mathrm{CDCl}_{3}$ at 300 and $75 \mathrm{MHz}$, respectively. Assignments were aided by ${ }^{1} \mathrm{H}$ COSY, TOCSY, DEPT, gHMQC and gHMBC analyses. NMR, nuclear magnetic resonance; DCEQA, 3,5-dicaffeoyl-epi-quinic acid.

and 40 units RNase inhibitor at $42^{\circ} \mathrm{C}$ for $60 \mathrm{~min}$ and at $72^{\circ} \mathrm{C}$ for 5 min using an automatic T100 Thermo Cycler (Bio-Rad Laboratories, Inc., Hercules, CA, USA). The target cDNA was amplified using the following sense and antisense primers: Forward 5'-GGA-GCC-AGC-TCC-CTC-TAT-TT-3' and reverse 5'-GGC-TAC-ATG-GGA-ACA-GCC-TA-3' for TNF- $\alpha$; forward 5'-AGA-AGG-AAA-TGG-CTG-CAG-AA-3' and reverse 5'-GCT-CGG-CTT-CCA-GTA-TTG-AG-3' for COX-2; forward 5'-AGT-TGC-CTT-CTT-GGGACT-GA-3' and reverse 5'-CAG-AAT-TGC-CAT-TGCACA-AC-3' for IL-6; forward 5'-CTG-TCC-TGC-GTG-TTG-AAA-GA-3' and reverse 5'-TTC-TGC-TTG-AGA-GGT-GCT-GA-3' for IL-1 $\beta$; forward 5'-AGG-GCA-TCA-TCA-ATT-TCG-AG-3' and reverse 5'-TGC-CTC-TCT-TCA-TCC-TTT-GG-3' for SOD-1; forward 5'-CAC-GCA-TAT-ACC-CGC-TAC-CT-3' and reverse 5'-AAG-GCG-GTC-TTA-GCC-TCT-TC-3' for HO-1; forward 5'-CCA-CAG-CTG-AGA-GGG-AAA-TC-3' and reverse 5'-AAG-GAA-GGC-TGG-AAA-AGA-GC-3' for $\beta$-actin. For the sqPCR amplification, the thermocycling conditions consisted of 30 cycles of $95^{\circ} \mathrm{C}$ for $45 \mathrm{sec}, 60^{\circ} \mathrm{C}$ for $1 \mathrm{~min}$ and $72^{\circ} \mathrm{C}$ for $45 \mathrm{sec}$. The final PCR products were separated by agarose gel (1.5\%) electrophoresis for $30 \mathrm{~min}$ at $100 \mathrm{~V}$. Gels were then stained with $1 \mathrm{mg} / \mathrm{ml}$ ethidium bromide and visualized by UV light using Davinch-Chemi imager ${ }^{\mathrm{TM}}$ (CAS-400SM, Seoul, Korea). Band densities were analyzed using MultiGauge software (v3.0; Fujifilm, Tokyo, Japan).
Immunoblotting. Western blotting was performed according to standard procedures. Briefly, cells were lysed in RIPA lysis buffer (Sigma-Aldrich; Merck KGaA, Darmstadt, Germany) at $4^{\circ} \mathrm{C}$ for $30 \mathrm{~min}$. Protein amount was measured using a bicinchoninic protein assay kit (cat. no. 23225; Thermo Fisher Scientific, Inc.) according to the manufacturer's protocol. Equal amounts $(25 \mu \mathrm{g})$ of protein samples were separated by $12 \%$ SDS-polyacrylamide gel electrophoresis, transferred onto a polyvinylidene fluoride membrane (Amersham Pharmacia Biotech; GE Healthcare Life Sciences, Little Chalfont, UK), blocked with 5\% skimmed milk for $1 \mathrm{~h}$ at room temperature and hybridized with the primary antibodies (diluted 1:1,000) overnight at $4^{\circ} \mathrm{C}$. Anti-COX-2 (cat. no. ab15191; Abcam, Cambridge, UK), anti-IL-6 (cat. no. ab6672; Abcam), anti-TNF- $\alpha$ (cat. no. ab9739; Abcam) and anti-superoxide dismutase (SOD)-1 (cat. no. sc-11407; Santa Cruz Biotechnology, Inc., Dallas, TX, USA) antibodies were polyclonal rabbit antibodies, while anti-IL-1 $\beta$ (cat. no. 12242; Cell Signaling Technology, Inc., Danvers, MA, USA), anti-heme oxygenase (HO)-1 (cat. no. sc-136960; Santa Cruz Biotechnology, Inc.), anti-Nrf-2 (cat. no. sc-365949; Santa Cruz Biotechnology, Inc.) and anti- $\beta$-actin (cat. no. sc-47778; Santa Cruz Biotechnology, Inc.) antibodies were polyclonal mouse antibodies. After incubation with horseradish-peroxidase-conjugated anti-mouse (cat. no. 7076; Cell Signaling Technology, Inc.) or anti-rabbit (cat. no. 7074; Cell Signaling Technology, Inc.) secondary antibodies (diluted 1:1,000) at room temperature for $1 \mathrm{~h}$, immunoreactive proteins were detected using a chemiluminescence ECL assay kit (Amersham Pharmacia Biosciences; GE Healthcare Life Sciences) according to the manufacturer's instructions. Western blot bands were visualized using a Davinch-Chemi imager ${ }^{\mathrm{TM}}$ (CAS-400SM, Seoul, Korea). Band densities were analyzed using MultiGauge software (v3.0; Fujifilm, Tokyo, Japan).

Statistical analysis. Data are presented as the mean \pm standard deviation of three repeated experiments. Differences between the means of the individual groups were analyzed using the analysis of variance (ANOVA) procedure of the Statistical Analysis System, SAS v9.1 (SAS Institute, Cary, NC, USA) followed by Duncan's multiple range tests. The correlation between treatment dose and cell viability was determined by Pearson correlation analysis, and the correlation coefficient was expressed as the $\mathrm{r}$-value. $\mathrm{P}<0.05$ was considered to indicate a statistically significant difference.

\section{Results}

Cytotoxicity of DCEQA and UVB exposure in HaCaT cells. Prior to the in vitro analysis of the protective effect of DCEQA against UVB-induced oxidative stress, its biocompatibility was tested by 3-(4,5-dimethylthiazol-2-yl)-2,5-diphenyl tetrazolium bromide (MTT) assay. Following a $48 \mathrm{~h}$ sample treatment at different concentrations (1,5 and $10 \mu \mathrm{M})$, DCEQA did not show any significant cytotoxicity in $\mathrm{HaCaT}$ cells compared to the control group (Fig. 1A). A negative correlation was found between the DCEQA dosage and viability of the $\mathrm{HaCaT}$ keratinocytes with a $\mathrm{LC}_{50}$ value of $372.53 \mu \mathrm{M}$. Although Pearson correlation analysis revealed 

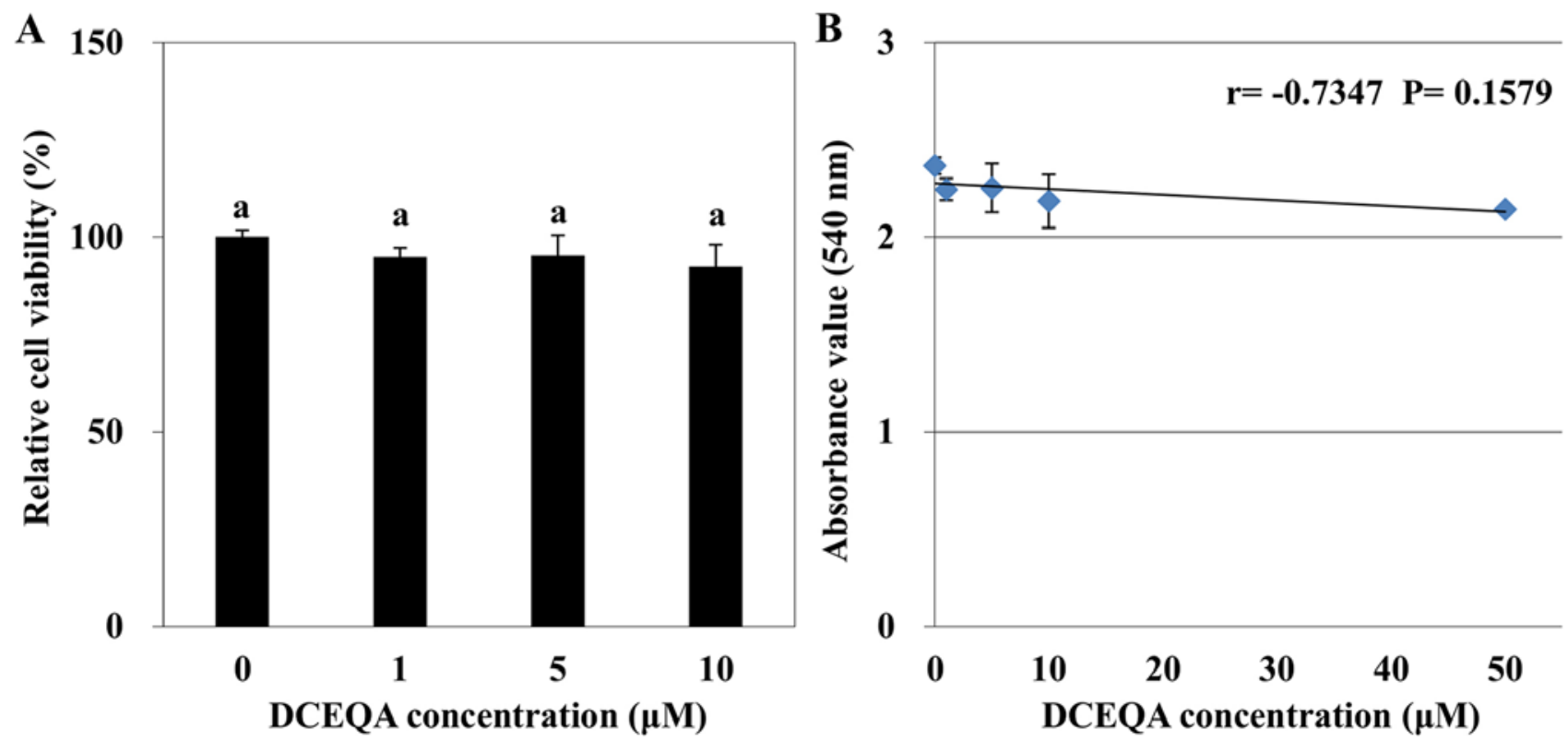

Figure 1. Effect of DCEQA on the viability of HaCaT cells (A). DCEQA did not show any significant cytotoxicity in HaCaT cells compared to the control group as observed by MTT assay. Cell viability following DCEQA treatment was evaluated by the ability of cells to form MTT-formazan crystals and measured by the absorbance values at $540 \mathrm{~nm}$. Viability of the cells was quantified as a percentage of the untreated $(0 \mu \mathrm{M})$ control. Values are expressed as means \pm SD $(\mathrm{n}=3)$. ${ }^{\mathrm{a}}$ Identical letters indicate absence of statistically significant differences $(\mathrm{P}>0.05)$. (B) Correlation between the DCEQA treatment concentration and cell viability was determined by Pearson correlation analysis (correlation coefficient $r=-0.7347, \mathrm{P}=0.1579$ ). DCEQA, 3,5-dicaffeoyl-epi-quinic acid.

that there was a moderate negative correlation $(r=-0.7347)$, among the tested concentrations ( 0 to $10 \mu \mathrm{M})$ the decrease in cell viability was not statistically significant $(\mathrm{P}=0.1579$; Fig. 1B). The first statistically significant decline in cell viability was observed for concentrations $>10 \mu \mathrm{M}$. Hence, subsequent assays were carried out using concentrations of DCEQA at 1,5 and $10 \mu \mathrm{M}$. The sufficient energy level of UVB irradiation was determined through the cell viability of HaCaT cells obtained from the MTT assay following exposure to different energy levels of UVB from 10 to $1,000 \mathrm{~mJ} / \mathrm{cm}^{2}$ for different time periods. After $24 \mathrm{~h}$ of UVB exposure at $15 \mathrm{~mJ} / \mathrm{cm}^{2}$ a rapid decline in cell viability was observed (data not shown). Therefore, this energy level was chosen as the appropriate level for further experiments.

Effect of DCEQA on UVB-induced intracellular ROS generation in HaCaT cells. Formation of intracellular ROS was evaluated using the colorimetric analysis of ROS generation-sensitive dye 2',7'-dichlorodihydrofluorescin diacetate (DCFH-DA). Evaluation of the potential scavenging ability of DCEQA on intracellular ROS generation was carried out by measuring the intensity of DCFH-DA conversion to highly fluorescent 2',7'-dichlorofluorescein (DCF) in the presence of ROS. UVB irradiation caused a sharp time-dependent increase in the DCF intensity indicating elevated oxidative stress. Treatment with DCEQA notably decreased the formation of DCF in a dose-dependent manner comparable to that of retinoic acid $(1 \mu \mathrm{M})$, which was used as a positive control, at the concentration of $10 \mu \mathrm{M}$ (Fig. 2). Results showed that DCEQA was able to reduce the generation of ROS either through its own ROS scavenging ability or by enhancing the intracellular scavenging mechanisms. Nevertheless, DCEQA significantly reduced the intracellular oxidative stress in HaCaT cells.

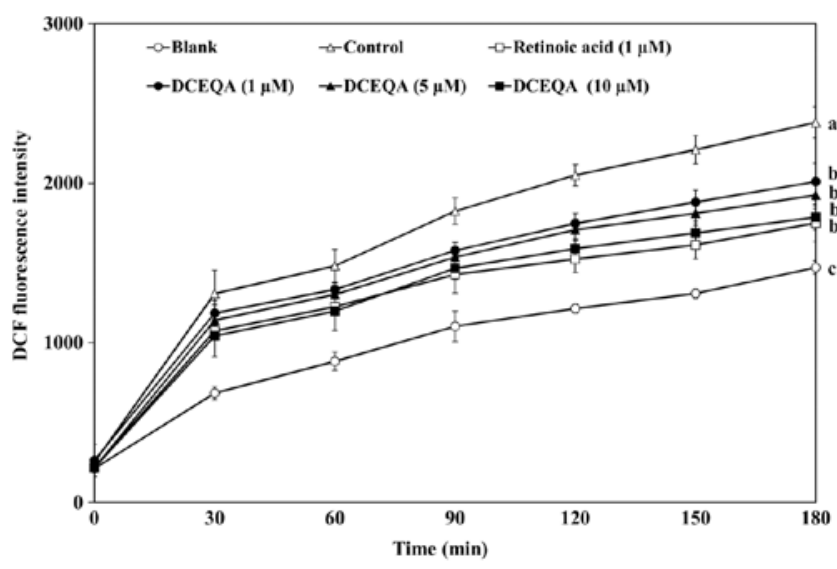

Figure 2. Effect of DCEQA on UVB irradiation-induced ROS generation in $\mathrm{HaCaT}$ cells. Values are expressed as the means $\pm \mathrm{SD}(\mathrm{n}=3) .{ }^{\mathrm{a}-\mathrm{c}}$ Different letters above the bars indicate statistically significant differences $(\mathrm{P}<0.05)$, while identical letters indicate no significant differences. Blank, non-irradiated cells non-treated cells; Control, UVB irradiated non-treated cells. DCEQA, 3,5-dicaffeoyl-epi-quinic acid; ROS, reactive oxygen species.

Effect of DCEQA on UVB-induced activation of the inflammatory response. As an attempt to determine the effects of DCEQA on UVB-induced expression of proinflammatory cytokines, both mRNA and protein expression levels of TNF- $\alpha$, COX-2, IL- 6 and IL-1 $\beta$ were investigated by RT-sqPCR and western blotting, respectively. The exposure of $\mathrm{HaCaT}$ cells to UVB irradiation resulted in elevated expression levels of all analyzed cytokines. UVB-induced mRNA (Fig. 3A) and protein (Fig. 3B) expression levels of TNF- $\alpha$, COX-2, IL-6 and IL-1 $\beta$ were lower in the DCEQA-treated keratinocytes than these levels in the UVB-irradiated control cells. All cytokines were significantly $(\mathrm{P}<0.05)$ reduced in terms of both mRNA and protein levels as compared to the untreated irradiated 


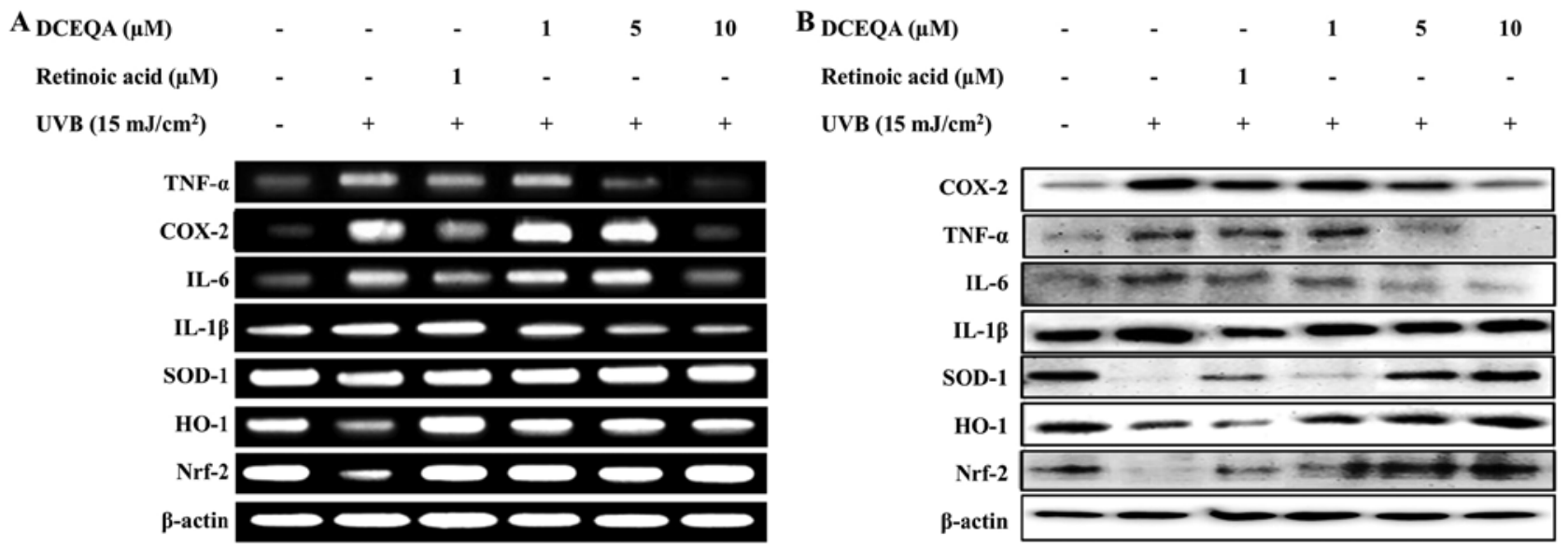

Figure 3. Effect of DCEQA on the UVB-induced expression of proinflammatory cytokines (TNF- $\alpha$, COX-2, IL-6 and IL-1 $\beta$ ), antioxidant enzymes (SOD-1 and HO-1) and Nrf2. (A) Effect of DCEQA on the mRNA levels of the cytokines, enzymes and Nrf2 was analyzed by RT-PCR. (B) Effect of DCEQA on the protein levels of the cytokines, enzymes and Nrf2 was analyzed by western blotting. DCEQA, 3,5-dicaffeoyl-epi-quinic acid; TNF- $\alpha$, tumor necrosis factor- $\alpha$; IL, interleukin; SOD-1, superoxide dismutase-1; HO-1, heme oxygenase-1; Nrf2, nuclear factor-like 2.

control cells according to quantification of RT-sqPCR (Fig. 4A) and western blot (Fig. 4C) bands. The present results showed that DCEQA can attenuate the UVB-linked activation of the proinflammatory response.

Effect of DCEQA on UVB-induced antioxidant enzyme expression through the nuclear factor-erythroid 2-related factor-2 (Nrf2) pathway. To investigate the effect of DCEQA on UVB-induced antioxidant enzyme expression, RT-sqPCR and western blotting were utilized to observe the mRNA and protein levels respectively for SOD-1 and HO-1. Following UVB exposure, $\mathrm{HaCaT}$ cells were shown to express diminished mRNA and protein levels of SOD-1 and HO-1. Cells treated with DCEQA exhibited significantly increased expression of SOD-1 and HO-1 in a dose-dependent manner (Fig. 3). Expression levels of both antioxidant enzymes were dose-dependently regulated by DCEQA to the levels prior to UVB irradiation according to the quantification of the bands (Fig. 4B and D).

In order to investigate the mechanism of action behind antioxidant enzyme upregulation, the effect of DCEQA on Nrf2 mRNA and protein levels were investigated with RT-sqPCR and western blotting, respectively (Fig. 3A and B, respectively). The expression of Nrf2 was significantly inhibited after UVB exposure. The presence of DCEQA resulted in activation of the Nrf2 pathway depicted as elevated mRNA (Fig. 4B) and protein (Fig. 4D) expression. This result suggests that DCEQA upregulated the antioxidant response of $\mathrm{HaCaT}$ cells through Nrf2-dependent activation of SOD-1 and HO-1 production.

\section{Discussion}

Oxidative stress plays a critical role in the progression of photoaging (31). Exposure to ultraviolet (UV) rays causes elevated oxidative stress in the cells forming the skin layers. UV-induced generation of intracellular ROS leads to upregulation of lipid peroxidation and collagen degradation, which are known causes of DNA damage and aging of the skin (7). Therefore, relieving the oxidative stress of skin cells is one of the main strategies for the prevention of skin photoaging.
Use of natural antioxidants with their biocompatibility and additional health benefits is a favorable approach in light of recent studies (32-34). Accordingly, several studies reported the antioxidant properties of CQA derivatives from different sources. In the present study, DCEQA significantly inhibited the UVB-induced intracellular ROS generation and proinflammatory response (Fig. 2).

UVB exposure is shown to lead to activation of mitogen activated protein kinase (MAPK) pathways due to increased ROS levels (13). This harmful increase in ROS levels activates the inflammatory response due to possible tissue damage. Coupled with elevated ROS, activation of the MAPK pathways leads to the upregulation of MMP production and degradation of skin collagen, which gives the strength and resiliency to the skin. Exposure to UVB stimulates the production of proinflammatory cytokines as a component of cellular damage such as TNF- $\alpha$, COX-2, IL- 6 and IL-1 $\beta$, which accelerates the photoaging process. The inflammatory response associated with UVB irradiation and mediated by these cytokines gradually increases ROS and other cytokine production augmenting the harmful effects of UV exposure (7). As showed by the suppressive effect of DCEQA on ROS levels, it was suggested that DCEQA also attenuates the inflammation of skin through these cytokines. As shown in Fig. 4A and B, DCEQA successfully downregulated the production of proinflammatory TNF- $\alpha$, COX-2, IL- 6 and IL- $1 \beta$ cytokines. This demonstrates that DCEQA prevents photoaging by inhibiting inflammation and therefore reducing skin damage.

Unscavenged free radicals in aging keratinocytes have been shown to gradually reduce antioxidant enzyme production, which further amplifies the photoaging effects of UVB irradiation (35). Several studies have reported that antioxidants also relieve the suppression of antioxidant enzyme production pathways (36). It is hence probable that DCEQA can affect intracellular antioxidant enzyme expression as DCEQA was shown to possess antioxidant properties. The results showed that UVB exposure caused significant suppression in the mRNA and protein expression of SOD-1 and HO-1 antioxidant enzymes which was upregulated following DCEQA treatment. During the regulation of antioxidant enzyme production and in 
$\mathbf{A}$
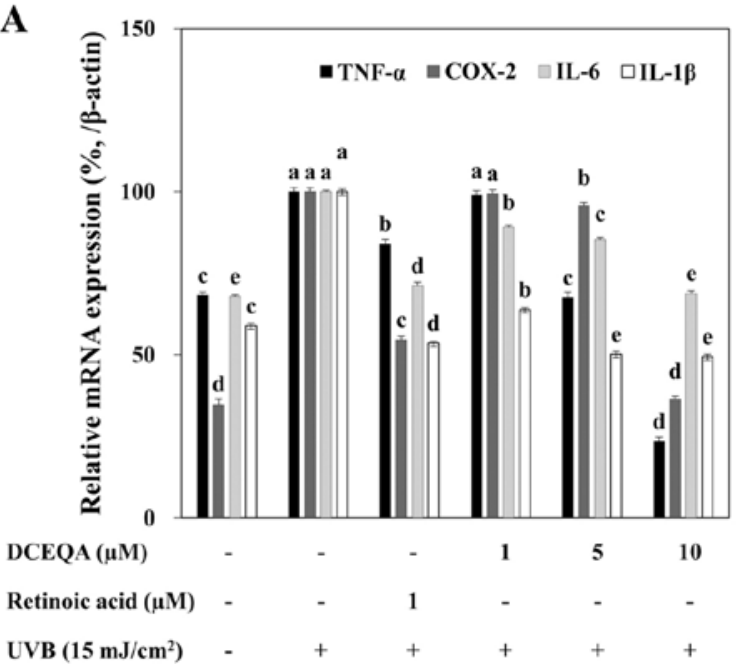

C

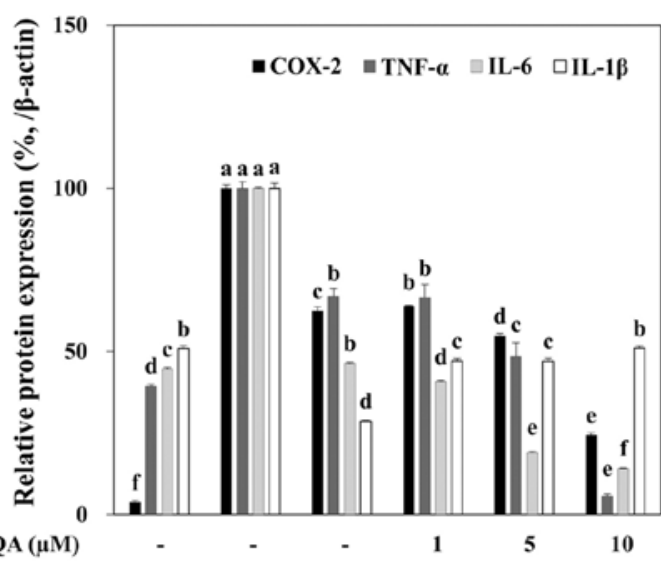

Retinoic acid $(\mu \mathrm{M})$

UVB $\left(15 \mathrm{~mJ} / \mathrm{cm}^{2}\right)$
B

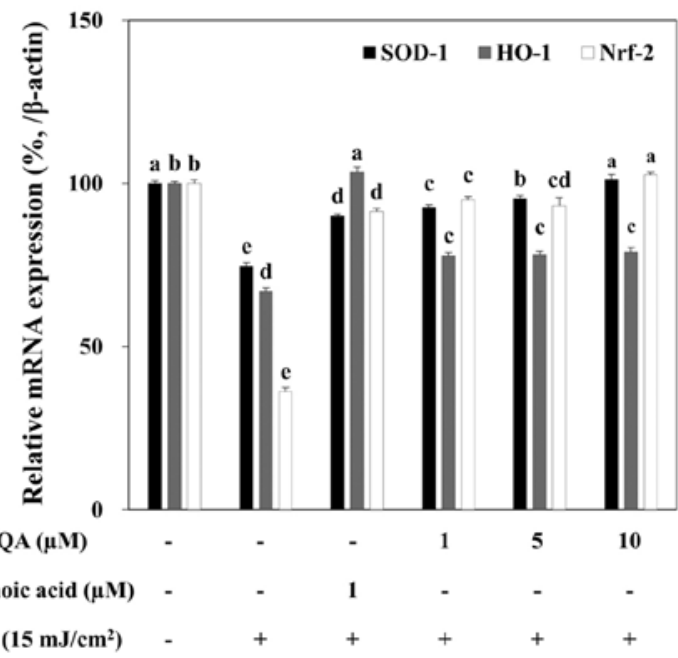

D

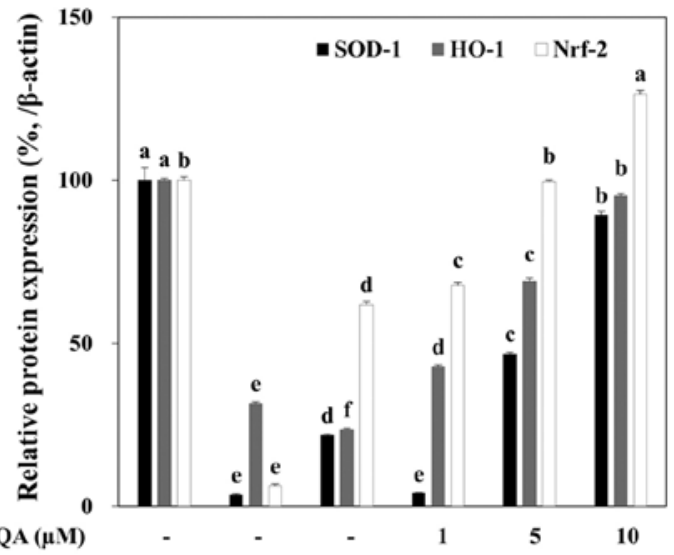

Retinoic acid $(\mu \mathrm{M})$

UVB $\left(15 \mathrm{~mJ} / \mathrm{cm}^{2}\right)$

Figure 4. Quantification of the effect of DCEQA on the UVB-induced expression of proinflammatory cytokines (TNF- $\alpha$, COX-2, IL-6 and IL-1 $\beta$ ), antioxidant enzymes (SOD-1 and HO-1) and Nrf2. The mRNA (A and C) and protein (B and D) levels were quantified by the density of the bands and normalized against the housekeeping gene and protein $\beta$-actin. Quantification of the expression levels was carried out through densitometric calculation and the data were normalized against housekeeping $\beta$-actin mRNA and protein. Effect of DCEQA treatment was plotted as the relative percentage to UVB-exposed untreated control cells $(A$ and $C)$ or untreated unirradiated blank cells $(C$ and $D)$. Values are expressed as the means $\pm S D(n=3)$. ${ }^{a-f}$ Different letters above the bars indicate statistically significant differences $(\mathrm{P}<0.05)$, while identical letters indicate no significant differences. DCEQA, 3,5-dicaffeoyl-epi-quinic acid; TNF- $\alpha$, tumor necrosis factor- $\alpha$; IL, interleukin; SOD-1, superoxide dismutase-1; HO-1, heme oxygenase-1; Nrf2, nuclear factor-like 2.

turn reducing the oxidative stress and photoaging process, the Nrf2 pathway plays a pivotal role (37). Production of oxidant metabolizing enzymes can neutralize the ROS damage in keratinocytes. Different CQA derivatives have been reported as antioxidants that can also regulate the Nrf2/Keap1 pathway while acting against oxidative stress-mediated cellular damage (38). In the present study, in addition to reducing intracellular ROS generation, DCEQA increased the expression of Nrf2 mRNA and protein.

DCEQA was tested in comparison to retinoic acid $(1 \mu \mathrm{M})$ as a positive control. Retinoic acid is evidently a strong antioxidant with skin protective effects against UV exposure. At the same concentration of $1 \mu \mathrm{M}$, retinoic acid was more effective than DCEQA. Yet, the results were notable, and the additional health benefits of DCEQA as indicated by several previous studies (39-41) suggest that the efficacy of DCEQA is comparable to retinoic acid and similar protective agents.
According to the results, the effective dose of DCEQA to be utilized was suggested to be between approximately $10 \mu \mathrm{M}$ and up to but below $50 \mu \mathrm{M}$ taking into account the possible cytotoxicity. As a derivative of caffeoylquinic acid, it was suggested that DCEQA exhibits its photoaging activity due to caffeoyl groups bound to quinic acids, which are important for CQA-based antioxidant activity. In addition, the cytoprotective activity of DCEQA can be credited to the caffeoyl moieties and the position of its cyclohexane skeleton when compared to similar CQA derivatives (42).

Upregulation of the Nrf2 pathways, which was observed to be inhibited by UVB irradiation was suggested to be the mechanism of action for DCEQA. One of the activation pathways of Nrf2 is the TNF signaling cascade including the pro-inflammatory response mediated by TNF- $\alpha$. Thus, it was suggested that upon DCEQA treatment, by attenuating the deteriorated $\mathrm{Nrf} 2$ pathway, antioxidant enzyme production was 
increased, and intracellular ROS generation was suppressed resulting in diminished inflammation. This resulted in a reduction in the UVB-linked damage in keratinocytes and halting of photoaging.

In conclusion, the present study demonstrated the protective effect of DCEQA against UVB irradiation-mediated damage in $\mathrm{HaCaT}$ keratinocytes, suggestively via ROS scavenging and increased antioxidant enzyme production through the Nrf2 pathway. Furthermore, DCEQA was able to downregulate proinflammatory cytokine production. Taken together, the present results demonstrated that DCEQA is a potential natural product to be utilized as a lead compound in the cosmetics field due to its anti-photoaging properties. However, future studies regarding the underlying mechanisms and potential scavenging effects on other free radicals will further enable the use of DCEQA in respective fields as a potent bioactive substance for skin protection.

\section{Acknowledgements}

Not applicable.

\section{Funding}

The present study was supported by the BB21+ Project in 2018 .

\section{Availability of data and materials}

The datasets used and/or analyzed during the present study are available from the corresponding author on reasonable request.

\section{Authors' contributions}

YS and CSK conceived the research idea, designed the experiments and supplied the necessary materials. JHO performed the experiments and collected the data. JIL conducted the isolation and chemical elucidation analysis. FK interpreted the data and drafted the manuscript. All authors read and approved the manuscript and agree to be accountable for all aspects of the research in ensuring that the accuracy or integrity of any part of the work are appropriately investigated and resolved.

\section{Ethics approval and consent to participate}

Not applicable.

\section{Patient consent for publication}

Not applicable.

\section{Competing interests}

The authors declare that they have no competing interests.

\section{References}

1. Fisher GJ, Kang S, Varani J, Bata-Csorgo Z, Wan Y, Datta S and Voorhees JJ: Mechanisms of photoaging and chronological skin aging. Arch Dermatol 138: 1462-1470, 2002.

2. Rittié L and Fisher GJ: UV-light-induced signal cascades and skin aging. Ageing Res Rev 1: 705-720, 2002.
3. Fisher GJ: The pathophysiology of photoaging of the skin. Cutis 75 (2 Suppl): S5-S9, 2005.

4. Ichihashi M, Ueda M, Budiyanto A, Bito T, Oka M, Fukunaga M, Tsuru K and Horikawa T: UV-induced skin damage. Toxicology 189: 21-39, 2003.

5. de Gruijl FR: Photocarcinogenesis: UVA vs. UVB radiation. Skin Pharmacol Appl Skin Physiol 15: 316-320, 2002.

6. Simon MM, Aragane Y, Schwarz A, Luger TA and Schwarz T: UVB light induces nuclear factor kappa B (NF kappa B) activity independently from chromosomal DNA damage in cell-free cytosolic extracts. J Invest Dermatol 102: 422-427, 1994.

7. Pillai S, Oresajo C and Hayward J: Ultraviolet radiation and skin aging: roles of reactive oxygen species, inflammation and protease activation, and strategies for prevention of inflammation-induced matrix degradation-a review. Int J Cosmet Sci 27: 17-34, 2005.

8. Herrling T, Jung K and Fuchs J: Measurements of UV-generated free radicals/reactive oxygen species (ROS) in skin. Spectrochim Acta A Mol Biomol Spectrosc 63: 840-845, 2006.

9. Yoshizumi M, Nakamura T, Kato M, Ishioka T, Kozawa K, Wakamatsu K and Kimura H: Release of cytokines/chemokines and cell death in UVB-irradiated human keratinocytes, HaCaT. Cell Biol Int 32: 1405-1411, 2008.

10. Yang WS and Stockwell BR: Ferroptosis: Death by lipid peroxidation. Trends Cell Biol 26: 165-176, 2016.

11. Briganti S and Picardo M: Antioxidant activity, lipid peroxidation and skin diseases. What's new. J Eur Acad Dermatol Venereol 17: 663-669, 2003.

12. Buckman SY, Gresham A, Hale P, Hruza G, Anast J, Masferrer J and Pentland AP: COX-2 expression is induced by UVB exposure in human skin: Implications for the development of skin cancer. Carcinogenesis 19: 723-729, 1998.

13. Kim AL, Labasi JM, Zhu Y, Tang X, McClure K, Gabel CA, Athar M and Bickers DR: Role of p38 MAPK in UVB-induced inflammatory responses in the skin of SKH-1 hairless mice. J Invest Dermatol 124: 1318-1325, 2005.

14. Suschek CV, Mahotka C, Schnorr O and Kolb-Bachofen V: UVB radiation-mediated expression of inducible nitric oxide synthase activity and the augmenting role of co-induced TNF-alpha in human skin endothelial cells. J Invest Dermatol 123: 950-957, 2004.

15. Bashir MM, Sharma MR and Werth VP: UVB and proinflammatory cytokines synergistically activate TNF-alpha production in keratinocytes through enhanced gene transcription. J Invest Dermatol 129: 994-1001, 2009.

16. Bosch R, Philips N, Suárez-Pérez JA, Juarranz A, Devmurari A, Chalensouk-Khaosaat J and González S: Mechanisms of photoaging and cutaneous photocarcinogenesis, and photoprotective strategies with phytochemicals. Antioxidants (Basel) 4: 248-268, 2015.

17. Lin TK, Zhong L and Santiago JL: Anti-inflammatory and skin barrier repair effects of topical application of some plant oils. Int J Mol Sci 19: pii: E70, 2017.

18. Wu PY, Huang CC, Chu Y, Huang YH, Lin P, Liu YH, Wen KC, Lin CY, Hsu MC and Chiang HM: Alleviation of ultraviolet B-induced photodamage by coffea arabica extract in human skin fibroblasts and hairless mouse skin. Int J Mol Sci 18: pii: E782, 2017.

19. De Luca C, Mikhal'chik EV, Suprun MV, Papacharalambous M, Truhanov AI and Korkina LG: Skin antiageing and systemic redox effects of supplementation with marine collagen peptides and plant-derived antioxidants: A single-blind case-control clinical study. Oxid Med Cell Longev 2016: 4389410, 2016.

20. Działo M, Mierziak J, Korzun U, Preisner M, Szopa J and Kulma A: The potential of plant phenolics in prevention and therapy of skin disorders. Int J Mol Sci 17: 160, 2016.

21. Katiyar SK: Dietary proanthocyanidins inhibit UV radiation-induced skin tumor development through functional activation of the immune system. Mol Nutr Food Res 60: 1374-1382, 2016.

22. Jiang XW, Bai JP, Zhang Q, Hu XL, Tian X, Zhu J, Liu J, Meng WH and Zhao QC: Caffeoylquinic acid derivatives protect SH-SY5Y neuroblastoma cells from hydrogen peroxide-induced injury through modulating oxidative status. Cell Mol Neurobiol 37: 499-509, 2017.

23. Tian Y, Puganen A, Alakomi HL, Uusitupa A, Saarela M and Yang B: Antioxidative and antibacterial activities of aqueous ethanol extracts of berries, leaves, and branches of berry plants. Food Res Int 106: 291-303, 2018. 
24. Roleira FM, Tavares-da-Silva EJ, Varela CL, Costa SC, Silva T, Garrido J and Borges F: Plant derived and dietary phenolic antioxidants: Anticancer properties. Food Chem 183: 235-258, 2015.

25. Liang $\mathrm{N}$ and Kitts DD: Role of chlorogenic acids in controlling oxidative and inflammatory stress conditions. Nutrients 8: pii: E16, 2015.

26. Kwak CS, Yang J, Shin CY and Chung JH: Topical or oral treatment of peach flower extract attenuates UV-induced epidermal thickening, matrix metalloproteinase-13 expression and pro-inflammatory cytokine production in hairless mice skin. Nutr Res Pract 12: 29-40, 2018.

27. Choi HS, Park ED, Park Y and Suh HJ: Spent coffee ground extract suppresses ultraviolet B-induced photoaging in hairless mice. J Photochem Photobiol B 153: 164-172, 2015.

28. Kim HJ and Lee YS: Identification of new dicaffeoylquinic acids from Chrysanthemum morifolium and their antioxidant activities. Planta Med 71: 871-876, 2005.

29. Miller SA, Coelho SG, Miller SW, Yamaguchi Y, Hearing VJ and Beer JZ: Evidence for a new paradigm for ultraviolet exposure: A universal schedule that is skin phototype independent. Photodermatol Photoimmunol Photomed 28: 187-195, 2012.

30. Oh JH, Seo Y and Kong CS: Anti-photoaging effects of solvent-partitioned fractions from Portulaca oleracea L. on UVB-stressed human keratinocytes. J Food Biochem 43: 25 Feb, 2019 doi.org/10.1111/jfbc.12814.

31. WenkJ,BrenneisenP,MeewesC,WlaschekM,PetersT,BlaudschunR, Ma W, Kuhr L, Schneider L and Scharffetter-Kochanek K: UV-induced oxidative stress and photoaging. In: Oxidants and antioxidants in cutaneous biology. Curr Probl Dermatol 29: 83-94, 2001

32. Saewan N and Jimtaisong A: Natural products as photoprotection. J Cosmet Dermatol 14: 47-63, 2015.

33. Pallela R, Na-Young Y and Kim SK: Anti-photoaging and photoprotective compounds derived from marine organisms. Mar Drugs 8: 1189-1202, 2010.
34. Mukherjee PK, Maity N, Nema NK and Sarkar BK: Bioactive compounds from natural resources against skin aging. Phytomedicine 19: 64-73, 2011.

35. Rabe JH, Mamelak AJ, McElgunn PJ, Morison WL and Sauder DN: Photoaging: Mechanisms and repair. J Am Acad Dermatol 55: 1-19, 2006.

36. Schmidt HH, Stocker R, Vollbracht C, Paulsen G, Riley D, Daiber A and Cuadrado A: Antioxidants in translational medicine. Antioxid Redox Signal 23: 1130-1143, 2015.

37. Rojo de la Vega M, Krajisnik A, Zhang DD and Wondrak GT: Targeting NRF2 for improved skin barrier function and photoprotection: Focus on the achiote-derived apocarotenoid bixin Nutrients 9: pii: E1371, 2017.

38. Saito Y, Tsuruma K, Ichihara K, Shimazawa M and Hara H: Brazilian green propolis water extract up-regulates the early expression level of HO-1 and accelerates Nrf2 after UVA irradiation. BMC Complement Altern Med 15: 421, 2015.

39. Oh JH, Lee JI, Karadeniz F, Seo Y and Kong CS: 3,5-dicaffeoyl-epi-quinic acid isolated from edible halophyte Atriplex gmelinii inhibits adipogenesis via AMPK/MAPK pathway in 3T3-L1 adipocytes. Evid Based Complement Alternat Med 2018: 8572571, 2018.

40. Ryu KJ, Yoou MS, Seo Y, Yoon KW, Kim HM and Jeong HJ: Therapeutic effects of Artemisia scoparia Waldst. et Kitaib in a murine model of atopic dermatitis. Clin Exp Dermatol 43: 798-805, 2018

41. Lee JY, Song DG, Lee EH, Jung SH, Nho CW, Cha KH and Pan $\mathrm{CH}$ : Inhibitory effects of 3,5-O-dicaffeoyl-epi-quinic acid from Gymnaster koraiensis on AKR1B10. J Korean Soc Appl Biol Chem 52: 731-734, 2009.

42. Miyamae Y, Kurisu M, Han J, Isoda H and Shigemori H: Structure-activity relationship of caffeoylquinic acids on the accelerating activity on ATP production. Chem Pharm Bull (Tokyo) 59: 502-507, 2011. 